\title{
THE
}

\section{The meaning of growing old: A lifeworld hermeneutic study on existential matters during the third age of life}

\author{
Lina Palmér \\ Maria Nyström \\ Gunilla Carlsson \\ Catharina Gillsjö \\ University of Rhode Island, cgillsjo@uri.edu \\ Irene Eriksson
}

See next page for additional authors

Follow this and additional works at: https://digitalcommons.uri.edu/nursing_facpubs

Creative Commons License

\section{(c) (7)}

This work is licensed under a Creative Commons Attribution 4.0 License.

\section{Citation/Publisher Attribution}

Palmér L, Carlsson G, Nyström M, Gillsjö C, Eriksson I, Dalheim Englund A-C (2019) The meaning of growing old: A lifeworld hermeneutic study on existential matters during the third age of life Healthy Aging Research 8:1-6. http://doi.org/10.35248/har.2019.8.8

Available at: http://doi.org/10.35248/har.2019.8.8

This Article is brought to you for free and open access by the College of Nursing at DigitalCommons@URI. It has been accepted for inclusion in College of Nursing Faculty Publications by an authorized administrator of DigitalCommons@URI. For more information, please contact digitalcommons-group@uri.edu. 


\section{Authors}

Lina Palmér, Maria Nyström, Gunilla Carlsson, Catharina Gillsjö, Irene Eriksson, and Ann-Charlotte Dalheim-Englund

This article is available at DigitalCommons@URI: https://digitalcommons.uri.edu/nursing_facpubs/40 


\title{
The meaning of growing old: A lifeworld hermeneutic study on existential matters during the third age of life
}

\author{
Lina Palmér ${ }^{a \star}$, Maria Nyströmª, Gunilla Carlssona, Catharina Gillsjöo ${ }^{\mathrm{b}}$, Irene Erikssonc, Ann-Charlotte \\ Dalheim-Englunda
}

This study investigates existential matters in the third age of life, which encompasses the years after retirement and ends when extensive support needs emerge in the fourth age. As the theoretical starting point in a lifeworld hermeneutic approach, 18 healthy older adults were interviewed about what it means for them to grow old. The interviews were interpreted according to Gadamer's principles of openness and Ricoeur's proposal to provide suggestions on how meaning can be explained. The findings are presented in three interpreted themes: Feeling free, Becoming vulnerable, and Existing in closeness to death. The themes are further interpreted, and a comprehensive understanding is reached with theoretical support from Jean-Paul Sartre's idea of factuality and project. The meaning of growing old is discussed in terms of positive factors, such as healthy aging, transition and gerotranscendence, but also in respect to concerns over future suffering in relation to illness and dependence. It is concluded that the freedom of the third age is greatly appreciated for a healthy life, but also threatened by increased risks of ill health. It is not morbidity in itself that worries most, but the risk of being dependent on care and support from others. This is important to consider when planning and performing care in order to promote a healthy aging.

Keywords: Caring science, Dependence on care, Existential matters, Healthy aging, Lifeworld hermeneutics

\section{Introduction}

Currently, there are over 600 million older adults in the world, and it is presumed that this figure will double by 2025. The average lifespan in Sweden is among the highest in Europe. In a population of 10 million in 2017, more than 2 million were over 65 years old ${ }^{[1]}$.

According to the World Health Organization (WHO) ${ }^{[2]}$, all persons over 65 are defined as older adults. With increased life expectancy, there is reason to doubt the definition of such a large age range as this. Many researchers, for example, Baltes and Smith [3], suggest that we need to recognize two phases of human ageing. Laslett ${ }^{[4]}$ develops further precision by adding a third and a fourth age, building upon a dividing line which is not bound to actual age.

Sponsorships or competing interests that may be relevant to content are disclosed at the end of this article.

aDepartment of Caring Science, Work Life and Social Welfare, University of Borås, Sweden

${ }^{b}$ Department of Health and Education, Sweden and College of Nursing, University of Rhode Island, Kingston, RI, USA

'Department of Health and Education, University of Skövde, Sweden

${ }^{*}$ Corresponding Author.: Department of Caring Science, Work Life and Social Welfare, University of Borås, Sweden Tel: +46-703669653. E-mail address: lina.palmer@hb.se (Lina Palmér).

Copyright $\odot 2019$ Palmér L, et al. This is an open-access article distributed under the terms of the Creative Commons Attribution License, which permits unrestricted use, distribution, and reproduction in any medium, provided the original work is properly cited.

Lina Palmer, et al. Healthy Aging Research (2019) 8:8

Received 12 May 2019; Accepted 25 July 2019

Published online 01 August 2019

DOI: 10.35248/har.2019.8.8
The third age starts in connection with retirement, where older adults usually still have good health and retain their physical and mental functions. The transition to the fourth age is not bound to any actual age; it occurs when functions are impaired and the need for support and assistance arrive, something that varies greatly at the individual level.

Knowledge about older adults is an extensive research field with different perspectives. It is dominated by medical issues, which may partly be explained by the fact that older adults over 84 years were for a long time mainly researched solely from that perspective ${ }^{[5]}$. Diseaseoriented research is based on the increased risk for various forms of illness such as cancer, cardiovascular disease, kidney disease, impaired vision and hearing and cognitive dysfunctions ${ }^{[6-11]}$. In such research, ageing means the increased risk for illness. As a consequence, many older adults think of themselves in terms of health problems ${ }^{[12]}$ and the research connected to this as 'misery research' ${ }^{[13-16]}$.

The unambiguous risk for diseases due to age also increases researchers' interest in how to promote healthy ageing and support for older adults to remain healthy and active for as long as possible ${ }^{[17}$ ${ }^{18}$. According to the $\mathrm{WHO}^{[2]}$ the quality of life in addition to longevity for older adults has become important in order to understand how to provide for comfort and meaningfulness in nursing homes ${ }^{[19]}$ or when various forms of illness occur ${ }^{[20-22]}$.

Research on conditions for older adults' well-being are not that common, but it has been suggested that older adults often estimate their health as relatively good, in spite of ill health. For example, Jolanki and Vilkko ${ }^{[23]}$ believe this means that people over 90 change their health perspective. Health problems are perceived as normal, and medical problems are accepted and tolerated without complete loss of the sense of well-being. However, some studies indicate differences between men and women to the health benefit of men 
${ }^{[24-26]}$. Josefsson et al. ${ }^{[24]}$ also found age differences. Older adults aged 65-79, rate their health as relatively good while, hardly surprising, the estimate of quality of health falls from $80-84$ years of age. This indicates a transition from the third to the fourth age ${ }^{[4]}$.

Overall, there is quite a lot of research on older adults linked to the fourth age, but there seems to be significantly less research on what it means to be in the third age ${ }^{[27]}$. Broström ${ }^{[28]}$ considered this as a complexity and suggests that the experience of ageing is an ongoing process.

However, in spite of the several perspectives on ageing in the research field, we know for sure that if we do not die young, we will all eventually face the challenges of ageing as individuals. It seems fair to assume that such challenges will raise existential matters that have been neither noticed nor processed during the younger years. Such research is missing in the field of caring science. In order to have the possibility to plan provide caring activities that enable older people to feel health and wellbeing it is important to understand what it means for them to grow old. Such knowledge will complement the existing knowledge of aging in a fruitful way. Therefore, the aim of this study is to explain and understand such existential matters in that period in life, which in the present study is referred to as the third age of life.

\section{Research Methodology}

This study is part of a Swedish project on healthy older adults' life situation. The project is conducted in the western part of Sweden which has 1.7 million inhabitants, of which more than $19 \%$ are over 65 years old.

\section{Epistemology}

Research on existential matters requires a lifeworld approach which focuses on the world as it is experienced, prior to any theories devised to explain it ${ }^{[29]}$. In a lifeworld approach, the main idea is to 'go to the things themselves'; in other words, such an approach is directed to a phenomenon. A phenomenon should be understood in terms of something as it is experienced (or lived) by a human being. The phenomenon in focus in this study is existential matters from the perspective of older adults who estimate their health as good. A lifeworld approach involves an open and sensitive attitude towards the phenomenon under study, in this case, existential matters from the perspective of older adults who rate their health as good. A lifeworld approach employs a variety of methods, identifying common threads ${ }^{[30-33]}$ concerning the nature of understanding. For the present empirical study, a lifeworld hermeneutic method ${ }^{[34]}$ is applied. This consists of an interpretative analysis with an open and pliable approach as inspired by Gadamer ${ }^{[33]}$ and Ricoeur ${ }^{[35]}$. The latter's ideas came into use for interpreting data at an explanatory level.

\section{Sample}

In the major part of the project, 520 participants completed a questionnaire about their lifestyle and a shorter version of sense of coherence (SOC) according to Antonovsky ${ }^{[36]}$. In connection with this, they were asked about their willingness to participate in the current part of the project. Those who agreed provided their telephone number. To provide for variations in data, participants were selected according to gender, variations in SOC and place of residence. The selection took place in two medium-sized Swedish cities with surrounding smaller towns and rural areas, and 23 seniors were asked again, now by telephone, if they still agreed to participate in the study. Six seniors had changed their minds, but 18 persons, seven men and eleven women, aged 72 to 91 years $(M=78)$ reaffirmed their agreement to participate. They were interviewed at places of their own choosing.

\section{Interviews}

This research explores the phenomenon of existential matters from the perspective of older adults who estimate their health as good through lifeworld interviews. Such interviews are directed towards the lived experiences of the phenomenon and focus on the meanings of the phenomenon ${ }^{[29]}$. The lifeworld interviews included four open-ended questions which can be used to begin the interview and direct attention to the phenomenon. The questions were:

- What does it mean for you to be older?

- What is most important in your everyday life?

- What does it mean to be healthy in old age?

- What do you think about the end of life?

According to principles of an open lifeworld approach ${ }^{[29]}$, the participants were encouraged to reflect upon and describe their personal thoughts and feelings concerning each question. Pliable, probing questions were asked as a way to inspire the participants to reflect upon matters not immediately described in order to deepen the understanding of the phenomenon. The interviews were audiotaped and then transcribed verbatim. The present study mainly analyses data from the first question about what it means to be an older adult. Statements based on the other questions will be analyzed in forthcoming articles.

\section{Analysis}

This study used the reflective lifeworld hermeneutical approach in the process of analysis ${ }^{[29]}$. In following this approach, we strived to follow Gadamer ${ }^{[33]}$ and his maxim that a hermeneutic attitude requires optimal openness and flexibility on the part of the researcher's pre-understanding in order for new insights to emerge. The interpretative procedure was also influenced by the hermeneutic philosophy of Ricoeur ${ }^{[35]}$ and his application of a questioning and critical approach. For this reason, theoretical support was used for the main interpretation and presented in the form of an overarching theme inspired by Jean-Paul Sartre's idea ${ }^{[37]}$ about factuality and project (briefly described in the findings).

The interpretative method ${ }^{[34]}$ followed the principles of wholeparts-new whole. It began when the first whole (the data set) was read and became familiar to the researchers. Statements corresponding to the aim of the study were identified according to meaning. Meaning units were compared for similarities and differences. Similarities were brought together, and three themes (i.e., parts of the phenomenon) were developed and interpreted. Finally, an interpretation was made that linked the three themes to an overarching theme (a new whole) that suggests how to understand the core of existential matters at the time of ageing where you still consider your health as good, i.e., the third age according to Laslett ${ }^{[4]}$.

During the interpretative work, the emerging meanings were consecutively compared with data to check that the interpretations did not only reflect what the researchers took for granted (which can be assumed to be more associated with the researchers' preunderstanding than with the actual data.) Any contradictions between data and interpretation were further investigated. The same was true when making sure that no data were omitted merely because they did not fit into any piece of the actual interpretations. If any weaknesses in that respect were found, the emerging interpretation was reconsidered, reworded or omitted. 


\section{Ethics}

Written information about the study was provided when the participants were asked whether they would be available for an interview after filling in the initial questionnaire. Those selected for participation were informed more fully about the aim of the study, that their participation was completely voluntary and that it was possible for them to withdraw from the study at any time. They were assured of confidentiality and that the analysis would be conducted with the intention to maintain the integrity and privacy of all participants.

\section{Results}

The findings are described and concluded with an interpretation of each theme's inherent meaning. Thereafter follows an overarching theme, which suggests how to understand all the core themes. The interpretations are clarified with quotes from data. It is worth noting that the meanings of the themes are not qualitatively different. They can occur both together and at different times during the period of life, which in this study is referred to as the third age.

\section{Feeling free}

During active professional work life, much energy is consumed by the work, making it important to rest during leisure time. Retirement is a completely new experience of not being governed by the routines that flow from a professional job. As a retiree, there is a feeling of freedom with much time for one to engage in everyday life, which creates opportunities for new interests and a more active social life. The ability to decide for yourself also entails new choices in view of all the new opportunities available. A sense of owning one's own time emerges. Two of the participants stated:

"You feel better after retirement. When I was working I was completely controlled by the job. When the evening came I had no energy left to do what I really wanted to do"

"The first thing I did after retirement was to turn off the alarm clock. I was free, I wasn't bound to anything. Now I can decide for myself what I want to do. I can solve crosswords late at night and sleep long time in the morning"

This newly acquired freedom means refraining from doing what has previously been felt as compelling. The demands associated with a job are replaced by freedom of choice in many of the small things of everyday life. Opportunities for spontaneity increase and this can easily include novel stimulating experiences without extensive planning. Having time to learn is good, and it feels important to try new things in order to keep up with societal development. To own and be able to control one's time also means not having to rush, being allowed to carry out things at one's own pace. Thus, retirement involves a sense of peace and quiet, and fewer demands to be perfect than were previously made. Two of the participants stated:

"Now you choose what you want to do and not want to do, so it's a lot of freedom"

"I have no claim to myself that everything should be perfect. I don't have to do it. I am free from such duties"

Yet, simultaneously there is an awareness that the newly acquired freedom will diminish gradually. This time of freedom can be short. One of the participants state:

"Take advantage of the day and do all you can! That day will come where you will suffer from ill health. I do not postpone anything. I do everything at once because you never know. Yet, at the same time, I plan ahead all the time. I am aware that it may not be possible [to implement it], but I am still planning"

\section{Existential interpretation}

After retirement, both early adulthood and middle age are completed, and a new period of life emerges. This period offers both great freedom and many new opportunities. When thinking about the future, one must bear in mind that it is important to take advantage of all opportunities as for long as possible. The unspoken hope seems to be that this period of life will be long because it is a privilege and luxury to be allowed to engage in one's own wishes at a mature age. In order to avoid the risk of losing opportunities when it becomes hard to execute them, it is important to decide what one currently wants to do. Feeling free as an older adult seems to presuppose the ability to take advantage of life here and now and simultaneously refrain from denying any problems that may arise in the future.

\section{Becoming vulnerable}

Becoming vulnerable involves the knowledge that the body will become more and more fragile and that there is the increasing risk of ill health in old age can only be controlled in the short term. But that does not prevent the hope of belonging to a group of older adults who live well at a very high age. It becomes important to increase such possibilities by living in a healthy way. Behind the healthy lifestyle can nevertheless be a fear of disabilities that entail dependence on support and help from others. This is described as:

"I think that food is important. We eat a lot of vegetables and fruits"

"Exercise is very good, so you do not get stiff in the body so that you can move easily. Many old people can't even get up from the floor"

"When we can't manage daily life by ourselves, then of course we enter the final stage of life. I am worried about being unable to take care of myself"

"If I am worried about something, it is to be sick and not be able to manage my ordinary life by myself"

Another frightening aspect of the vulnerability that accompanies old age is the resulting sorrow and loneliness if one's partner or any other close and dear person passes away. To support a close relative who is physically or mentally ill can be both demanding and compelling. Feelings of compulsion can easily turn into a consciousness and fear of regretting actions, or lack of actions, when everything is over. Two participant's states:

"I think about how amazing it is to still be a couple. But one knows that one of us will pass away before the other, and then my husband says: 'I hope that it will be me. I can't manage on my own"

"I must make sure that I will not have to regret anything. I will be there until he dies. I wish I could do something for myself, but, at the same time, I wouldn't feel good about that"

When someone else passes away, it causes sorrow, but sometimes also a person's own life becomes appreciated to a higher degree than before. Supporting friends who have lost a closely related person can contribute to gratefulness for continuing to live, simultaneously with a feeling that death can come as a liberator. One participant describe:

"I went to a 96-year-old's funeral last week. She was demented and that is tragic. Then you think that it is good to end, because being demented is not a real life"

\section{Existential interpretation}

Becoming vulnerable, facing the risk of suffering from disease, being disabled or becoming an informal caregiver means that a free and independent existence disappears. Caring for a sick person who is close to you can create feelings of doing a meaningful task, and that can become something positive. But, it can also be perceived as a burden, a duty that must be done. Individually, a situation dominated by one's own or a closely related person's ill health may 
have different meanings and lead to different concrete strategies for managing the situation. Regardless, it becomes ever so hard to ignore the insight that it can be difficult to completely recover from serious illness in old age.

\section{Existing in closeness to death}

Living close to death as an older adult prompts thoughts about beginning the end of life, the meaning of life and what it means to be human. One participant states:

"It is the meaning of life that is the greatest existential issue. Where do I come from, where am I now and where am I going"

Existing in closeness to death awakens a fear of bodily changes that reminds one about forthcoming death. Such fear also encompasses anxiety about weakness and tiredness, which adversely affect life and the possibility to live and do all the things one wants to do before death is a reality. Ageing and, more markedly, existing in closeness to death provoke the thought that life is unfathomable-there are no guarantees about the last age of life and how it will be. The fear is to that one will end life in illness and dependence. This is a frightening thought. Before disability and illness strike, it is possible to maintain a distance from death. But, through illness, death creeps closer, and the thoughts of it can no longer be forced away. It may feel necessary to avoid thinking about death by avoiding encounters with people in life-threatening situations, because such meetings remind one too much of one's own closeness to death. The participants stated:

"It has creeped inside. At the same time, one has to understand that life is finite. But I'm putting it forward. I have not yet planned my funeral"

"Now it's time to take advantage of life. Because when I was sick I was totally gone for one hour. And that was really dangerous"

"If I only socialize with light happy people, then I do not think about death. If I visit acquaintances who feel bad and have cancer, then I may also feel bad. The mere sight of this often puts me in a position where I'm not feeling well"

Growing old in good health can also bring feelings of guilt because of the relief of not being severely ill or dying as soon as some of one's peers. This can also highlight a willingness to live life to the fullest extent and take advantage of all of life's opportunities. The closeness of death can thus make life's meaning extremely clear, so that the motto 'now or never' becomes highly applicable. Such concerns are stated as:

"When you feel good, you may feel guilty when you meet peers who do not also feel well"

"I take advantage of the day and do everything I can now. That day will come when you get a disease, and then you have to accept it. It's going to happen to everyone, that's it"

"I have acquaintances that have passed away in this age, 82-84 years. When they died, I thought that I would not have many years left, so now I am in a hurry"

\section{Existential interpretation}

Ageing means that one increasingly realizes that life will soon be lived in the presence of death in a much more noticeable way than during earlier years. The horizon of life is actually tearing up in the distance, regardless of illness or not. The closeness to death implies a persistent feeling of being persecuted by something uncertain and uncontrollable. Death is occasionally manifested in the form of illness and death in the environment. But, death as a phenomenon is an inescapable part of human existence, like a shadow, a constant companion, which remains by one's side at every instant of life. Yet, it is not death or being dead that scares people the most; rather it is the idea of not being alive anymore. The desire to live is strong, and it unequivocally balances with the unavoidable finites that death implies.

\section{Overarching theme: Accepting the facts of life yet ena- bling new projects.}

Jean-Paul ${ }^{[37]}$ suggested that a person's life commutes between factuality (fact) and project as two existential categories. Factuality is the anchoring of that which has already occurred or is already performed, while project is the planned, the extension of existence into the future. Factualities thus consist of our lived experiences and the circumstances we live in. Projects consist of planning and implementing new opportunities. This interaction is dialectic. For a young person, life is often filled with important projects. When they are carried out, they transform into new factuality's. When, for example, the project 'professional education' has been completed, the newly acquired competence transforms into a factuality, which in turn becomes the starting point for a new project.

Older adults' projects are not as long-term as projects during their younger days. Now, their attention focuses on the here and now. The important projects of young life, such as choosing a life partner or a single life, having children or not, choosing a professional career and other long-term commitments, are over. Instead, there is much of something that used to be in short supply: time! When professional life becomes limited and is finally finished completely, the older adult faces a new factuality and, simultaneously, a need for new projects. The third part of life has begun, and now it is important to live it in the best way that the new situation brings with it. It feels good to both own one's time and to be able to assist when grown children and friends need help. It feels even better to be stimulated by new interests, and to engage in both old and new interpersonal relations. Participation in cultural activities, associations or travel are high on the wish list of new projects.

At the same time, the realization that nothing lasts forever becomes more obvious than before. Apart from the freedom that comes with retirement, there is a factuality that cannot be disregarded: ageing means being more vulnerable than previously. Those who still are in good health are reminded of their vulnerability when their partners or other peers become sick or die.

Still, even though living with a partner can feel like a privilege, there are two risks involved: to be an informal caregiver or to be left alone. One's own death seems, however, not as scary as the risk of being forced to live alone or be dependent because of disabilities. In connection to this, we can also glimpse an implicit lack of confidence in society's ability to provide for professional care that enables dignity to be maintained even if one's cognitive ability or bodily functions fail.

Faced with the risk of being dependent on help, a new project emerges: to maintain health as long as possible. This creates motivation for a healthy lifestyle with exercise and good dietary habits. However, when the healthy lifestyle is based on fear of ill health, it can easily turn into a duty, and the sense of freedom that was so strong after retirement could vanish without notice. Yet, the attempt to maintain health cannot completely put away the thoughts of death as an upcoming factuality. This insight makes it urgent to not postpone all the things that feel important to do while there is still time to do them.

However, thinking about one's own death does not seem to be as scary as the risk of being forced to live an alienated and unworthy life. If that occurs, the fineness of life can be the last form of freedom, an escape from something worse. Perceiving death as a freedom can 
be a reason to desire to end life before it is dominated by too many losses-loss of beloved people, loss of bodily health, loss of memory and other cognitive functions, and, perhaps most detrimental, loss of dignity. Before life's last factuality, only one project remains: to accept the unwavering end of life with a feeling of having well used its opportunities.

\section{Discussion}

This study has researched the meaning of growing old through interpretations that suggest how to understand existential matters in the period of life that Laslett et al. ${ }^{[4]}$ introduced as the third age. Thus, the findings concern the years between perceived freedom after retirement and the fourth age's decline of functions. This period seems to take place between new possibilities and the inevitable end of life.

The findings indicate that there is a transition and a process that varies over time, giving rise to different feelings such as ambivalence and uncertainty. Benktson et al. ${ }^{[38]}$ describes those links as transitions that either close a person off or provide power to find new ways. According to Erik H. Erikson et al. ${ }^{[39]}$, transition covers all phases of life with eight ages based on each other, and with different challenges for each individual to handle. If the ageing adult has developed a sense of responsibility and care for others during previous developmental ages, the transition to the eight ages is characterized by integrity, which in turn makes it possible to value and summarize one's own life.

Erikson's et al. ${ }^{[39]}$ 'the life cycle completed' is, however, supplemented by his wife and co-worker, Joan Erikson, with a ninth age, where she claims that old adults often dissolve time and space perspectives in a way that allows for a deepened spirituality. Her ninth age was, in turn, influenced by the Swedish sociologist Lars Tornstam et al. ${ }^{[40]}$, who developed a theory of gerotranscendence to describe maturity and wisdom at old age. According to Tornstam's et al. ${ }^{[40]}$ theory, positive ageing involves new insights into the fundamentality's of life. In the present study, comprehensive understanding may be linked to this because integrity and wisdom can perhaps be considered as a prerequisite for the last project, that is, to accept and sometimes even embrace death as an escape from a declining quality of life. To take advantage of the potential of the third age, and simultaneously reflect on the changes during the fourth age, including the inevitable end of life, presumably requires such maturity and integrity that both Erikson et al. ${ }^{[39]}$ and Tornstam et al. ${ }^{[40]}$ suggest. If so, such a development indicates that the transition to late life can make more sense than younger people can ever imagine.

Hoogland et al. ${ }^{[41]}$ addresses similar issues in a focus group and found a transition of beliefs that led to an increased appreciation of life, general equanimity and increased acceptance, concluding that the way we view the world is constantly evolving, parallel with feelings of constancy. In a literature review, Baltes et al. ${ }^{[3]}$ reinforce the positive description of the third age, but with considerable concerns about the fourth age. They emphasize that neither society nor the individual should deny the problems that often occur in and follow from that period of life.

In order to understand the deeper existential dimensions of vulnerability related to ageing, Todres et al. ${ }^{142]}$ theory of well-being and their framework for delineating caring for vulnerability can give further meaning to the findings of the present study. In this view, suffering may form a foundation for empathic care. Vulnerability is described as a bodily phenomenon in terms of facing the risk of suffering from disease or being disabled, as well as loneliness if a loved one dies. Both risks are included in human life, especially during older years. Eriksson et al. ${ }^{[43]}$ describes suffering both in relation to illness and to poor, instrumental or neglected forms of care and in relation to life itself. In the present study, both these dimensions of suffering are visualized in the shape of existential concerns related to vulnerability. Consistent with such concerns, suffering in relation to care can probably emerge. In the present study, this kind of suffering was not directly mentioned but seems to appear between the lines in statements about not wanting to be dependent on support and assistance. Here, the present study highlight a fear of being forced to live an alienated and unworthy life. In caring science, such matters are notable as existential concerns related to unworthy forms of care.

In the last theme in the present study, existing in closeness to death, one's own death or the risk of losing a loved one is highlighted. From a caring science perspective, for example, in Eriksson's theory of suffering ${ }^{[43]}$, such loneliness can be understood as an existential suffering, a threatening factuality, which is important to consider in the efforts to develop high-quality care. Loneliness is, above all, related to the death of other people. It can, therefore, also be understood in relation to intersubjective dimensions in accordance with Todres et al. ${ }^{[42]}$, meaning that intersubjectivity refers to oneself in relation to others. Such existential dimensions can be even further elaborated from the perspective of Merleau-Ponty et al. ${ }^{[31]}$, who states that we exist in a world together with others, and we share the world with them. Thus, we are part of an embodied world in which others always exist and make life meaningful. The present study shows that such embodiment may become fragile in old age. Losing close relations means an abrupt alteration of an often long-lasting intersubjectivity wherein the connection to the world changes. This indicates blurring boundaries even in relation to the third age while still healthy.

Overall, the findings of this study make it reasonable to suggest that older adults' existential matters in many ways resemble those which follow us throughout life. To this a new insight is added when realizing that you belong to the oldest currently living generation, which is next to pass away. The meaning of this has both individual and general dimensions, yet with the common potential for maturity and dignity as suggested by Eriksson et al. ${ }^{[39]}$ and Tornstam et al. ${ }^{[40]}$.

\section{Conclusion and Further Research}

The freedom of the third age is highly appreciated, but also threatened by increased vulnerability. It is not morbidity in itself that worries the most, but the risk of being dependent on care and assistance from others. This makes it important to know more about how confidence in society's ability to provide high-quality care that alleviates suffering and preserves dignity can be improved. It also means further development of caring science with yet another deepening of the existential meaning of life in closeness to death. This issue will be addressed in an upcoming article.

\section{Acknowledgement}

We would like to acknowledge the older adults who generously participated in this study.

\section{Conflict of Interest}

None to report.

\section{Funding/Support}

The study was funded by Faculty of Caring Science, Work and 
Welfare, University of Borås, Sweden and the School of Health and Education, University of Skövde, Sweden.

\section{References}

1. Statistical yearbook: Stockholm Statistics, Sweden 2017.

2. World Health Organization (WHO). Definition of an older or elderly person. World Health Organization; Geneva, Switzerland, 2013.

3. Baltes PB, Smith J. New frontiers in the future of aging: From successful aging of the young old to the dilemmas of the fourth age. Gerontology 2003;49:123-135.

4. Laslett P. A fresh map of life. The emergence of the third age. Cambridge: Harvard University Press, London, UK, 1991.

5. Lennartsson C, Agahi N, Hols-Salen L, et al. Data resource profile: The Swedish panel study of living conditions of the oldest old. Int J Epidemiol 2014;43:731-738.

6. Resnick B, McLeskey SW. Cancer screening across the ageing continuum. Am J Manag Care 2008;14:267-276.

7. Dhingra R, Ramachandran SV. Age as a cardiovascular risk factor. Med Clin North Am 2012;96:87-91.

8. Tonelli M, Riella M. Chronic kidney disease and the ageing population. Indian J Nephrol 2014;24:71-74.

9. Agmon M, Limor L, Doumas M. The association between hearing loss, postural control, and mobility in older adults: A systematic review. J Am Acad Audiol 2017;28:575-588.

10. Calkins MP. From research to application: Supportive and therapeutic environments for people living with dementia. Gerontologist 2018;58:114-128.

11. Nicholsson L. Person-centred care: Experiences of older people with dementia. Nur Std 2017;32:41-52.

12. Alftberg A. What's the age of An ethnographic study on ageing, body and materiality. Lund Sweden: The University of Lund. Institute for Kulturvetenskap, Sweden, 2012.

13. Blaakilde AL. Does time run from Kronos? The meaning of chronology for perceptions of age. The meaning of ageing. Lund, Sweden, 2007.

14. Jönsson H. Introduction in aging, age order, ageism. Linköping University of Interdisciplinary Studies, Sweden 2009; 10.

15. Kontos PC. Local biology: Bodies of difference in ageing studies. Ageing \& Society 1999;19:677-689.

16. Kontos PC. Ethnographic reflections on selfhood, embodiment and Alzheimer's disease. Ageing \& Society 2004;24:829-849.

17. Bouaziz W, Lang, PO, Schmitt E, et al. Health benefits of multicomponent training programmes in seniors: A systematic review. Int J Clini Prac 2016;70:520-536.

18. Milte $\mathrm{C}, \mathrm{McNaughton} \mathrm{S}$. Dietary patterns and successful ageing: A systematic review. Eur J Nutr 2016;55: 423-450.

19. Leegaard M, Utne I, Halvorsrud L,et al. A review of selfrated generic quality of life instruments used among older patients receiving home care nursing. Health Soc Care Community;2018;26:321-328.
20. Balogun SA, Balogun R, Rasheed P, et al. Quality of life, perceptions, and health satisfaction of older people with end stage renal disease: A systematic review. J Am Geriatr Soc 2017;65:777-785.

21. Hill NL, McDermott C, Mogle J, et al. Subjective cognitive impairments and quality of life: A systematic review. Int Psychogeriatr 2017;29:1965-1977.

22. Montana CL, Bhorade AM. Glaucoma and quality of life: Fall and driving risk. Curr Opin Ophthalmol 2018; 29:35-140.

23. Jolanki O, Vilkko A. The meaning of a "sense of community" in a Finnish Senior co-housing community. J Hou Eld 2012;29:111125.

24. Josefsson K, Andersson M, Erikstedt A. Older adults' self-rated health and differences by age and gender: A quantitative study. Heal Agi Res 2016;5:1-10.

25. Singh L, Arokiasami P, Singh PK, et al. Determinants of gender differences in self-rated health among older population: Evidence from India. SAGE Open 2013;(3):1-12.

26. Yong V, Saito Y, Chan A. Gender differences in health and health expectancies of older adults in Singapore: An examination of diseases, impairments, and functional disabilities. J Cross Cult Gerontol 2011;26:89-203.

27. Gilbert C, Haggerty D, Taggert HM. Exploring factors related to healthy aging. Self Depe Nur 2012;19:20-25.

28. Broström M. Older people's perceptions on their own future, dying and death. University of Linköping: Studies in Arts and Science, Sweden 2014.

29. Dahlberg K, Dahlberg H, Nyström M. Reflective Lifeworld Research. Lund, Sweden, 2008.

30. Husserl E. Logical investigations. London: Routledge \& Kegan Paul, UK, 1970.

31. Merleau-Ponty M. Phenomenology of perception. London: Routledge, UK, 1962.

32. Heidegger M. Being and time. New York: Harper Perennial, 2008.

33. Gadamer HG. Truth and method. New York: The Continuum Publishing Company, 1960.

34. Nyström M. Lifeworld hermeneutics as epistemology and method of applied qualitative research in health care. Lund: Studentlitteratur, Sweden, 2017.

35. Ricoeur P. Interpretation theory. Discourse and the surplus of meaning. Fort Worth: Texas Christian University Press, 1976.

36. Antonovsky A. Health, stress and coping. San Fransisco: Jossey Bass, 1979.

37. Sartre JP. Existentialism and Marxism. Stockholm: Aldus/ Bonniers, 1971.

38. Benktson BE. Border situations: Questions on the meaning of life in the light of existential philosophy. Lund: Liber, Sweden, 1976.

39. Eriksson EH. The life cycle completed. Stockholm: Natur \& Kultur, 2004. 
40. Tornstam L. Gerotranscendence. A developmental theory of positive aging. New York: Springer Publishing Company;2005.

41. Hoogland, A. I. (2015). Continuity of change: The dynamic of beliefs, values and the ageing experience. Journal of Aging Studies 2015; (32):32-38.
42. Todres L, Galvin K. Caring and well-being. A lifeworld approach. New York: Routledge Studies in the Sociology of Health and Illness; 2013.

43. Eriksson K. The suffering human being. Chicago: Nordic Studies Press; 2006. 